\title{
Milagros de curación en la tradición médica tardo-antigua
}

\author{
Juan Carlos Alby \\ UNIVERSIDAD CATÓLICA DE SANTA FE - ARGENTINA \\ jcalby@hotmail.com
}

Resumen: La taumaturgia en la medicina se halla ampliamente atestiguada en antiguos documentos judíos y cristianos. El milagro interactuaba con el acto terapéutico racionalmente orientado, configurando una téchne iatriké, no resulta sencillo separar magia, religión, filosofía y medicina. La categoría antropológica "hombre divino" (theiós anér), con base en la antigüedad clásica, respaldaba los relatos de milagros y se extendía sobre, Jesús de Nazareth y Apolonio de Tiana. Es posible extraer de la primera literatura cristiana, canónica y apócrifa, de los escritos del judaísmo post-bíblico, y de la filosofía helénica, ideas fundamentales sobre el dinamismo cósmico y la centralidad del hombre como campo de convergencia de esas fuerzas conjuradas por el que realiza la curación.

Palabras clave: Asclepio; milagro; Jesús de Nazareth; Apolonio de Tiana; theiós anér.

Abstract: Medical thaumaturgy has been broadly proved in old Jewish and Christian. Miracle interacted with the therapeutic act, rationally directed, configuring a téchne iatriké it was not simple to separate magic, religion, philosophy and medicine. The anthropologic concept "divine man" (theiós anér), with basis on the Classical Age, supported of miracle stories and was associated with Jesus of Nazareth and Apollonius of Tyana. It is possible to extract from Christian literature, canonical and apocryphal, from postbiblical writing of Judaism and Hellenic philosophy; fundamental ideas of cosmic dynamism and the centrality of man as convergence point of these forces of healing.

Keywords: Asclepius; miracle; Jesus of Nazareth; Apollonius of Tyana; theiós anér. 


\section{INTRODUCCIÓN}

Durante los tres primeros siglos de la era cristiana, en el período que recibe la denominación historiográfica de antigüedad tardía, la medicina se hallaba cimentada en las intuiciones fundamentales de Hipócrates y de la escuela metódica fundada por Themiston de Laodicea y Tésalo de Trales, a las cuales se le agregaron en el siglo II las prácticas quirúrgicas de Galeno, iniciador por excelencia del pensamiento anatómico. La práctica médica oscilaba entonces entre la especulación teorética, propia de la escuela de Cos, y las teorías características de los metódicos que, por su simplicidad, tuvieron gran suceso en Roma ${ }^{1}$. Hacia mediados del siglo II a. C., apareció también la escuela empírica fundada por Filino de Cos bajo la influencia del escepticismo de Pirrón de Élide y Timón de Filunte. Se oponían a los dogmáticos buscando las causas inmediatas de los fenómenos y rechazando como inútiles las causas últimas, por considerar que la naturaleza como tal es incomprensible ${ }^{2}$. Otorgaron valor solamente a los datos de la experiencia y de la observación clínica, rechazando por crueles e inútiles la vivisección y disección de cadáveres humanos ${ }^{3}$.

El surgimiento del cristianismo que pregonaba el Reino de Dios como núcleo central de su mensaje, aportó al acto médico un nuevo elemento que, si bien se encontraba presente en las tradiciones que remontaban hasta el mismo Asclepio, adquiere en el horizonte cristiano el estatuto de signo (semeíon) de la presencia del Reino de los Cielos en la temporalidad humana. De esta manera, lo que se conoce como milagro irrumpe en la téchne iatriké de la época con características muy diferentes de las de los sueños de incubación de los que invocaban a Asclepio.

1 Esta escuela atribuía todas las enfermedades al estado de las paredes porosas o canales por donde discurren los distintos fluidos del cuerpo. Estos estados podían variar entre la tensión, el relajamiento o una mezcla de ambos. Consideraban prescindible el conocimiento anatómico para el diagnóstico y tratamiento de las enfermedades, por no advertir la relación necesaria que estas guardan con la estructura orgánica. Cfr. P. Laín Entralgo, Historia de la medicina (Salvat, Barcelona, 1978) 63-81.

2 Cfr. Platón, Leyes IX, 857c, en Platón. Diálogos VIII: Leyes (Libros VI-XII), traducción y notas de F. Lisi (Gredos, Madrid, 2007) 201.

3 Como método de tratamiento fundaron el llamado "trípode de los empíricos", basado en observaciones propias referentes al caso (ej., autopsía), datos acumulados por la experiencia (ej., historia) y, en caso de enfermedades nuevas, analogía con otros padecimientos similares (ej., epilogismos o homoíou metábasis). 
El presente trabajo se propone estudiar los milagros de curación tanto en la tradición grecorromana como en la judeocristiana. Seguidamente, se tratará acerca de la interferencia con la figura del médico de la noción de hombre divino (theiós anér) que se proyectaba sobre una práctica médica en que la creencia religiosa, la magia y la técnica propiamente empírica y especulativa estaban unidas sin demarcaciones notorias, hasta que la erradicación de la componente religiosa en el acto médico por parte de la medicina racionalista afectó la integridad de la concepción antropológica sobre la cual debe necesariamente apoyarse una medicina que tenga en cuenta la totalidad del hombre.

\section{MILAGROS DE CURACIÓN EN LA TRADICIÓN GRECORROMANA}

La noción de milagro entre los griegos no tiene el mismo significado que en la teología cristiana, según la cual, con este término se hace referencia a todo lo obrado por Dios por fuera o por encima del orden natural. La palabra latina miraculum, prodigio, portento, maravilla, deriva del verbo mirari, admirarse, maravillarse ${ }^{4}$ y es la traducción del griego thaûma, proveniente del verbo thaumázo, admirarse. En una cosmovisión caracterizada más por la creencia en el dinamismo del cosmos y la simpatía entre el macro y microcosmos que por una concepción elaborada de ley natural, todo aquello que causa asombro o estupor entre los hombres, es producto del ejercicio de una dýnamis especial que no es exclusiva de los dioses, sino que también es compartida por algunos hombres.

Existen numerosos testimonios sobre la proliferación de santuarios taumatúrgicos en el período helenístico y romano de los dos primeros siglos de nuestra era, así como también acerca de la creencia en la intervención divina con propósitos terapéuticos.

Entre estas deidades, destacan con preferencia Isis y Asclepio. La primera, junto a su consorte Serapis, producen la sanación o iatrikê a los indigentes $\mathrm{y}$, a la vez, mantienen el orden del universo, tarea en la que Isis había sustituido a $\mathrm{Ma}^{\prime} \mathrm{at}^{5}$. Dos aspectos caracterizaban la interven-

4 Cfr. L. MACChI, Diccionario de la lengua latina. Latino-español, español-latino (Don Bosco, Buenos Aires $\left.{ }^{6} 1966\right)$ 347. Para la relación entre las voces miraculum y taumaturgia, ver S. SEgURA MURGUía, Diccionario por raices del Latín y de las voces derivadas (Universidad de Deusto, Bilbao, 2006), 430.

5 Cfr. H. C. KeE, Medicina, milagro y magia en los tiempos del Nuevo Testamento (El Almendro, Córdoba, 1992) 103. 
ción curativa de Isis: su epiphaneía o "presencia" y su energetikón o "beneficencia”. Su acción benéfica se manifestaba en los sueños de quienes la invocaban, en cualquier lugar de la oikouménê habitada, como lo señala Diodoro Sículo, ya que sus santuarios se habían multiplicado desde el Mediterráneo oriental hasta las islas Británicas, sin excluir a Roma y las grandes ciudades de la Europa Occidental. La aretalogía de Isis, cuyo origen puede remontarse al siglo II a. C., presenta la intervención de la diosa como compensadora del fracaso de los médicos, sin aludir a técnicas conocidas en la medicina de la época. Antes bien, su sola epiphaneía nocturna producía la curación de la enfermedad, cuya etiología también es silenciada en este género de alabanzas. Un testimonio de Diodoro de Sicilia al respecto resulta elocuente:

"Presentándose en los sueños da a los pacientes remedios contra las enfermedades y cura sorprendentemente a quienes le obedecen; y muchos desahuciados por los médicos por la gravedad de la enfermedad, son sanados por ella; y un gran número, totalmente privados de la vista o de alguna otra de las partes del cuerpo, cuando se amparan en esa diosa, son restituidos a su anterior condición"6.

Afirmaciones como la precedente han conducido a algunos autores a pensar que en la época que nos ocupa existieron tres tipos de medicina, a saber, una medicina mágica, otra religiosa y, finalmente, una medicina técnica ${ }^{7}$. De acuerdo con esto, la secuencia cronológica se habría dado

6 Diodoro de Sicilia, Bibliotheca historica I, 25, 5, en Diodoro de Sicilia. Biblioteca Histórica. Libros I-III, traducción y notas de Francisco Parreu Alasà (Gredos, Madrid, 2001) 196.

7 Así por ejemplo, E. B. Tylor y J. E. Frazer. Según el primero, la cultura o civilización en sentido etnográfico es un todo complejo que incluye el conocimiento, las creencias, el arte, la moral, el derecho, las costumbres y cualesquiera otros hábitos y capacidades adquiridas por el hombre en cuanto miembro de la sociedad" (Cultura primitiva [Ayuso, Madrid, 1977] cap. 1). De acuerdo con esto, magia, religión y medicina constituyen tres instituciones que forman parte de la cultura en sentido objetivo. Tylor considera que la magia se rige por dos mecanismos mentales: las leyes de la semejanza según el clásico principio hómoios homoíoi, similla similibus, lo semejante con lo semejante que lleva a las nociones de contagio/contacto y la ley del tabú descrito por Frazer como magia negativa, que actúa por los mismos principios de asociación, según los cuales, las cosas que alguna vez estuvieron en contacto entre sí continúan actuando a distancia. Cfr. L. GIL, "Medicina, religión y magia en el mundo griego", en: A. Piñero (ed.), En la frontera de lo imposible. Magos, médicos y taumaturgos en el Mediterráneo antiguo en tiempos del Nuevo Testamento (El Almendro, Córdoba, 2001) 122; también, G. Bueno, "Medicina, magia y 
del siguiente modo. Primero, una medicina mágica correspondiente al estadio primitivo del pensamiento mágico, fracasada la cual, es sucedida por una medicina religiosa caracterizada por la creencia en seres poderosos. Finalmente, una medicina técnica resultante del descubrimiento de las leyes naturales. Esta concepción se ve seriamente cuestionada por la evidencia de que tanto ayer como hoy estos tres tipos de medicina coexisten y el recurso a cualquiera de ellos obedece al modo de experimentar la enfermedad y depende de la psicología individual.

El culto a Asclepio proporciona una prueba de ello, en vistas de que en el ritual religioso de la enkoimesis o incubatio aparecen tanto elementos mágicos como recetas propias de la téchne iatrikê hipocrática. Por lo tanto, la creencia de que la curación de la enfermedad se producía por la intervención directa de este dios, no era incompatible con aquella según la cual, Asclepio actuaba a través de la ciencia médica de la época. Es más, ambas se reúnen en la venerada figura de Galeno, quien si bien no es contado entre los funcionarios del templo de Asclepio, ya que entre estos y el médico de Pérgamo se establece una clara distinción ${ }^{8}$, es considerado no obstante como un therapéutes Asklepiou, pues era consciente de que la mano del dios guiaba tanto su carrera profesional como su vida personal ${ }^{9}$. Sin rechazar la capacidad curativa de Asclepio, Galeno consideraba que el dios tenía las limitaciones propias de la materia y que sus poderes no se distinguían demasiado de los que el gran médico atribuía a la naturaleza. Afirmaba, por ejemplo, que Asclepio no puede crear de la nada, motivo este por el cual polemizó contra los cristianos ${ }^{10}$.

El culto a Asclepio irrumpe con gran fuerza en los finales de la época arcaica, en que descollaba la figura del héroe médico prerrogativamente encarnada en Apis, el iatrómantis (médico adivino), fundador de Apia en la Argólide. Hasta entonces, Asclepio no era incluido entre los dioses

milagros. (Conceptos y estructuras mentales). Planteamiento filosófico", en A. Piñero, En la frontera de lo imposible..., Apéndice, 290, n. 2.

8 Según los Testimonios de Asclepio, 498-499 (L. Edelstein y E. J. Edelstein, Asklepios Testimonies I (Johns Hopkins Press, Baltimore, 1945).

9 Resulta conocido el relato según el cual, Galeno se opuso a acompañar en un viaje al emperador Marco Aurelio por expresa prohibición de Asclepio, lo que lo salvó de un naufragio. Cfr. H. C. KeE, Medicina, milagro y magia..., 95.

10 Cfr. la "Introducción" de Luis García Ballester a la obra de Galeno Sobre la localización de las enfermedades (De locis affectis), traducción y notas de SALUD Andrés Aparicio (Gredos, Madrid, 1997) 22. 
curadores, cuya dynamis particular era la iatriké (curativa), lo cual puede corroborarse en el canto $\mathrm{V}$ de la Ilíada, según el cual el médico de los dioses era Paeion ${ }^{11}$ y, junto a él, Apolo, con quien se fundió en el ritual ${ }^{12}$. Tampoco los hijos de Asclepio, los médicos Podalirio y Macaón, habían sido divinizados en los poemas homéricos ${ }^{13}$. El culto a Asclepio comienza en Tricca de Tesalia, de donde se extiende por la Grecia central y el Peloponeso. El traslado de su santuario desde Epidauro en el 420 a. C. hasta Roma en la isla tibertina hizo escala en distintos sitios, tales como Atenas, el Pireo y la isla de Cos -antes de la instalación en esta última de una escuela de medicina técnica- y estuvo rodeado de portentos, según relatos de Tito Livio y de Ovidio ${ }^{14}$.

11 "Y las toleró también el ingente Hades cuando el mismo hijo de Zeus, que lleva la égida, disparándole en Pilo veloz saeta, lo entregó al dolor entre los muertos con el corazón afligido, traspasado de dolor - pues la flecha se le había clavado en la robusta espalda y abatía su ánimo- fue al palacio de Zeus, al vasto Olimpo, y como no había nacido mortal, lo curó Paeion, esparciendo sobre la herida drogas calmantes". (Homero, Ilíada V, 401). Atacado por Diomedes con su propia lanza y con la ayuda de Palas Atenea, el dios Ares, herido y doblegado por el dolor, acudió a Zeus, quien ordenó a Paeion que lo curara: "Paeion le sanó, aplicándole drogas calmantes; que nada mortal en él había: Como el jugo cuaja la blanca y líquida leche cuando se le mueve rápidamente con ella, con igual presteza curó al furibundo Ares, a quien Hebe lavó y puso lindas vestiduras. Y el dios se sentó al lado de Zeus Cronión, ufano de su gloria”. (Homero, Il. V, 900).

12 Véase la nota 22 de Marta Alesso y Alejandra Regúnuga a Homero, Ilíada, V, 400ss., trad. de Luis Segallá y Estalella, Introducciones de Pedro Henríquez Ureña y Marta Alesso (Losada, Buenos Aires, 2005) 172.

13 “'¡Oh Néstor Nelida, gloria insigne de los aqueos! Ea, sube al carro, póngase Macaón junto a ti, y dirige presto a las naves los solípedos corceles. Pues un médico vale por muchos hombres, por su pericia en arrancar flechas y aplicar drogas calmantes'. Dijo; y Néstor, caballero gerenio, no dejó de obedecerle. Subió al carro, y tan pronto como Macaón, hijo del eximio médico Asclepio, le hubo seguido, picó con el látigo a los caballos y estos volaron de su grado hasta las cóncavas naves..." (HOMERO, Il. XI, 511-520).

14 Cfr. Tito Livio, Historia de Roma desde la fundación de la Ciudad X, 47, 11, traducción y notas de J. A. Villar Vidal, introducción general de Á. SierRa DE Cózar. Revisado por J. Gil (Madrid, Gredos, 1990) 377. Cfr Ovidio, Metamorfosis XV, 625-744, en P. Ovidi Nasonis Metamorpfosen, edición bilingüe latín-español, traducción de Ana Pérez Vega (Bruguera, Parets del Valles-Barcelona, 1983) 320. Según estos relatos, el dios había dado su conformidad para el traslado de su centro de culto, lo cual fue corroborado por la presencia de una serpiente que, saliendo del santuario, subió a bordo del barco que transportaba la estatua de Asclepio y se mantuvo expectante mientras la nave remontaba la corriente del Tíber, hasta dar indicios inequívocos de cuál debía ser su nueva morada, a saber, la isla tibertina. 
Los milagros de Asclepio acontecían durante los sueños de incubación, durante los cuales los enfermos, exigidos a pasar una noche completa en el ábaton, zona baja del santuario rodeada por un triple círculo de muros y a la que se accedía por varias puertas, eran visitados por el dios en sus manifestaciones oníricas o en la presencia de sus sacerdotes, así como de los perros y serpientes sagradas. Hacia el final de la época helenística y romana, el carácter filantrópico y afable de Asclepio hizo fácil su asociación con otras divinidades curadoras, tales como Isis y Serapis. Su simpatía por los esclavos y enfermos, le valió el título de sotêr, salvador, conservador, lo que motivó la reacción por parte de los Padres de la Iglesia, preocupados por la similitud entre el dios y la figura de Cristo. Tanto uno como otro eran hijos de un dios, curaron enfermos, devolvieron la vida a un muerto y, condenados a morir, ambos ascendieron a los cielos y se mostraron a sus fieles en forma corpórea.

Sin negar la efectividad de los milagros de Asclepio, los Padres instan a sus lectores a confiar más en el carácter divino de los milagros de Cristo, atribuyéndoles a los del dios pagano un origen demoníaco ${ }^{15}$.

Justino, refiriéndose a la superioridad de Jesús sobre Asclepio, dice:

"Cuando nosotros decimos también que el Verbo, que es el primer retoño de Dios, nació sin comercio carnal, es decir, Jesucristo, nuestro maestro, y que este fue crucificado y murió y, después de resucitado subió al cielo, nada nuevo presentamos, si se atiende a los que vosotros llamáis hijos de Zeus. Porque vosotros sabéis bien la cantidad de hijos que los escritores por vosotros estimados le atribuyen a Zeus: [...] Asclepio, que fue médico y, después de haber sido fulminado, subió al cielo [...] En fin, que (Jesús) sanara a cojos y paralíticos y enfermos de nacimiento, y resucitara muertos, también en esto parecerá que decimos cosas semejantes a lo que cuenta haber hecho Asclepio"16.

Por su parte, Clemente de Alejandría señala la similitud entre un epigrama del santuario de Asclepio y una cita del Evangelio:

"Eso era también lo que pretendía decir indirectamente el que escribió, fuera quien fuera, en el pórtico del templo de Epidauro: «Es ne-

15 Cfr. Tertuliano, A lospaganos II, 14, 9-14, Biblioteca de Patrística 63, introducción, traducción y notas de Jerónimo Leal (Ciudad Nueva, Madrid, 2004) 139s.

16 Justino, I Apología 21, 1-2; 22, 6, en D. Ruiz Bueno, Padres Apologetas griegos (s. II), edición bilingüe completa griego-español (BAC, Madrid, $\left.{ }^{3} 1996\right)$ 204-206. 
cesario que sea puro quien entra en un templo que perfuma incienso; mas, pureza es pensar cosas santas». "Y si no os hacéis como estos niños, no entraréis -dice (el Señor)- en el reino de los cielos» ${ }^{17}$. Así se manifiesta el templo de Dios, sentado sobre el triple fundamento de la fe, la esperanza y la caridad"18.

También Lactancio se refiere a Asclepio en numerosas ocasiones, entre ellas, aludiendo a su origen vergonzoso por la unión del dios Apolo con la mortal Corónide, hija del rey tesalio Flegias ${ }^{19}$ y cuestionando la sabiduría de Sócrates por haber rogado a sus familiares al momento de su muerte, el sacrificio de un gallo a este $\operatorname{dios}^{20}$.

"Temió sin duda que Esculapio le acusara de no haber cumplido su voto ante el juez Radamanto. Si hubiese muerto de una enfermedad, yo pensaría que este hombre estaba loco. Pero, como dijo estas cosas estando en sus cabales, el loco es quien piense que era un sabio" ${ }^{21}$.

Contrarios a los supuestos intereses mercenarios de este dios, los cristianos, cuyo culto reemplazó al de las divinidades paganas curadoras, se llaman a sí mismos anárgyroi, no cobradores ${ }^{22}$.

\section{MILAGROS DE CURACIÓN EN LA TRADICIÓN JUDEOCRISTIANA}

En el judaísmo, la actitud de los sabios hacia los milagros resultaba un tanto ambigua, pues si bien reconocían la realidad de los mismos, les preocupaba la posibilidad de que fueran confundidos con actos de magia, severamente censurados en la Ley ${ }^{23}$. De ahí que el acento estaba puesto sobre el hecho de que Dios es el autor del milagro, antes que en el acto portentoso en sí. El relato de Éxodo 7-9 sobre la célebre contienda

\section{Mt 18, 3 .}

18 Clemente de Alejandría, Strómata V, 13, 3-4; en Clemente de Alejandría. Strómata IV-V: Martirio cristiano e investigación sobre Dios, Fuentes Patrísticas 15, edición bilingüe griego-español preparada por Marcelo Merino Rodríguez (Ciudad Nueva, Madrid, 2003) 335.

19 Cfr. LaCtancio, Instituciones divinas I, 10, 1; en Lactancio. Instituciones divinas. Libros I-III, Introducción, traducción y notas de E. SÁNCHEZ SALOR (Gredos, Madrid, 1990) 97.

20 Cfr. Platón, Fedón 118b, en C. García Gual (Introducción, traducción y notas), Platón. Diálogos III (Gredos, Madrid, 2006) 140.

21 LACTANCIO, Instituciones divinas III, 20, 17, 316.

22 Cfr. L. Gil, "Medicina, religión y magia en el mundo griego", 129.

23 Cfr. Lv 19, 26-28; Dt 18, 10-14. 
entre Yahvé, por medio de Moisés, y los magos de Faraón Janes y Jambres, es una muestra de esta inquietud.

Entre el siglo II a. C. y el I de nuestra era, se produce un cambio tanto en la concepción de la enfermedad como en la valoración del médico, transformación que se encuentra atestiguada en numerosos documentos. En el Antiguo Testamento, la enfermedad era entendida como fruto del pecado y la imagen del médico, tanto en las tradiciones profética como histórica y sapiencial, es presentada con rasgos marcadamente peyorativos $^{24}$. Acudir al médico en vez de a Yahvé, era suficiente para que la gravedad de una enfermedad se incrementara ${ }^{25}$. La literatura deuterocanónica del período helenístico, revela de qué manera la influencia griega con su respeto por el orden natural, en términos de sympatheía y antipatheía, como necesario para el bienestar del hombre, fue transmutando la consideración de la figura del médico en Israel. Pero la diferencia entre la cosmovisión griega y la judía radica, en este aspecto, en que los israelitas atribuyen a Dios la soberanía sobre la naturaleza, que de ninguna manera responde a un orden autónomo.

Así, Ben Sirá afirma que el médico recibió de Dios el conocimiento de las potencias naturales y que los remedios han sido creados en la tierra por Dios:

"Honra al médico por los servicios que presta, que también a él lo creó el Señor. Del Dios Altísimo viene la curación, del rey se reciben las dádivas. La ciencia del médico le hace caminar con la cabeza alta, y es admirado por los poderosos. El Señor ha creado medicinas en la tierra, y el hombre prudente no las desprecia [...]. Él es quien da a los hombres la ciencia, para que lo glorifiquen por sus maravillas. Con las medicinas el médico cura y elimina el sufrimiento, con ellas el farmacéutico prepara sus mezclas"26.

Más adelante, el Sirácida deja en claro que la curación procede de Dios, y que caer en manos de un médico puede ser la consecuencia de apartarse del Hacedor:

24 Con excepción de Gn 50, 1-3, en que se relata el cuidadoso proceso de embalsamamiento del cuerpo de Jacob, encomendado por su hijo José a los médicos egipcios.

25 Cfr. el caso de Asá y su enfermedad de los pies, en 2 Cr 16, 11-12.

26 Eclo 38, 1-7. 
"Hijo, en tu enfermedad, no te desanimes, sino ruega al Señor, que él te curará. Aparta tus faltas, corrige tus acciones y purifica tu corazón de todo pecado. Ofrece incienso, un memorial de flor de harina y ofrendas generosas según tus medios. Luego recurre al médico, pues el Señor también lo ha creado; hay momentos en que la solución está en sus manos. También ellos rezan al Señor, para que les conceda el poder de aliviar el dolor, curar la enfermedad y salvar la vida. El que peca contra su Hacedor, ¡que caiga en manos del médico!”27.

Alrededor la misma fecha de la redacción del Sirácida, se produjo una crispación de la demonología en Israel que impactó de modo directo en la concepción de la enfermedad, pues a partir de entonces fue considerada como la consecuencia de la actividad demoníaca. Correlativamente, la cura de la patología se orienta hacia el modo de conjurar la acción de estas entidades. Precisamente, el ángel que aparece en la literatura del judaísmo helénico neutralizando la acción de los demonios, tanto en el

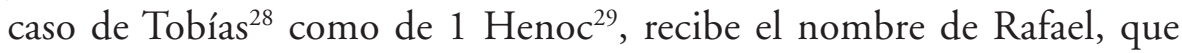
significa "Dios sana". Textos como este, perteneciente al género de la apocalíptica judía que proliferó durante la época helenística del judaísmo tardío, revelan la creencia de que el orden cósmico vigente se halla bajo el dominio de poderes contrarios a Dios que han influido a las autoridades, tanto religiosas como políticas, quedando solo un remanente de fieles a Yahvé que, obligados a soportar grandes tribulaciones, han de ser testigos y jueces en el día de la gran venganza en que Dios irrumpirá de manera decisiva contra la impiedad. Dios liberará a sus fieles con grandes signos y prodigios, tal como lo profetiza el libro de Daniel ${ }^{30}$. La restauración de la salud de la tierra irá acompañada de milagros de

Eclo 38, 9-15.

28 Rafael ayudó a Tobías no solo a sanar la ceguera de su padre causada por la caída de excremento de gorrión en sus ojos (Tob 2, 10; 11, 1-14), sino también a expulsar de Sarra, su prometida, al demonio Asmodeo que había sido causa de la muerte de sus siete esposos anteriores en la misma noche de bodas (Tob 3, 7-9; 8, 1-13).

29 Noé imparte instrucciones a Rafael para que ate a los ángeles malvados que se habían unido a las mujeres procreando la perversa raza de los nefilim ("vigilantes", Gn 6,1s.), además de haber enseñado a los hombres conocimientos médicos bajo la forma de la magia: “... conjuros y encantamientos, así como el modo de cortar raíces y haberle familiarizado con las plantas”. (1 Henoc 7, 1-6; 8, 3). Los ángeles caídos resultan confinados en prisiones eternas y se proclama que la tierra será sanada (1 Henoc 10, 4-7).

30 Cfr. Dn 3, 23-33. 
curación, tales como la apertura de la vista a los ciegos, la recuperación del oído para los sordos y del habla para los mudos ${ }^{31}$.

En este marco escatológico se presentan los milagros de curación realizados por Jesús según los evangelios sinópticos, como signos de la presencia germinal del Reino de Dios entre los hombres, inaugurando "los tiempos del fin". Sus curaciones y exorcismos resultan escandalosas a la luz de los rituales judíos y de las prescripciones de la Ley. Tan es así que curaba en día sábado (Mc 3, 1-6), se arrogaba el poder de perdonar los pecados que, según se creía, eran causa de la enfermedad que sanaba (Mc 2, 1-12); curaba a personas que no se caracterizaban por el ideal judío de la piedad (Lc 19, 1-10) o que no pertenecían a su raza (Mt 7 , 24-30), realizaba milagros en lugares paganos (Mc 1, 40-45) y, en clara confrontación con las prescripciones rituales, tocaba a un leproso (Mc 1, 10-45) y dejaba que sus vestidos sean tocados por una mujer con flujo menstrual (Mc 5, 25-34). Estos hechos constituyen el núcleo de la respuesta de Jesús a la pregunta de Juan el Bautista acerca de si era él quien había de venir o habría que esperar a otro: "Id y contad a Juan lo que oís y veis: los ciegos ven y los cojos andan, los leprosos quedan limpios y los sordos oyen, los muertos resucitan y se anuncia a los pobres la buena Nueva”. A lo que agrega, a modo de señal distintiva de su misión, una expresión que proclama la necesidad de que estos hechos trasciendan las fronteras rituales y geográficas y que a un hombre como Juan, con un celo exacerbado por una purificación que asegure la pertenencia al pueblo de la Alianza, podría sonar como subversiva: “[...] ¡y dichoso aquel que no halle escándalo en mí!”32.

Entre la terminología utilizada para la enfermedad y la referida a su curación en los relatos de milagro en la tradición cristiana, se advierte una relación muy ajustada. En sentido general, la enfermedad es denominada nósos, dolencia, morbo (Mt 10, 1), asthéneia, enfermedad, malakía, debilidad (Mt 10, 1); en sentido metafórico, básanos, tormento, mástix, azote, plaga (Mc 3, 10). Es importante el uso del verbo synékhesthai, estar atado, ya que tiene como contrapartida apolyein, desatar, lo cual nos lleva directamente a la acción curativa basada en una concepción materialista de la etiología de la enfermedad, como es el caso de la mujer inclinada de Lc 13, 10-17, a la que Jesús le dijo: "Mujer, estás suelta de

\footnotetext{
Cfr. Is 35, 1-10

32 Mt 11, 4-6.
} 
tu enfermedad, y le impuso las manos". Frente al reproche del principal de la sinagoga por haber realizado la curación en día sábado, Jesús responde: "Hipócritas, ¡cada uno de vosotros no desata en sábado a su buey o a su asno del pesebre y lo lleva a beber? Y esta, que es hija de Abraham, a la que ató Satanás hace dieciocho años, ¿no debía ser desatada de esta atadura en día sábado?” (v. 15). Con esta respuesta, Jesús apunta directamente a una de las treinta y nueve actividades prohibidas en día sábado, la de atar y desatar camellos o barcos. Si los judíos infringían el precepto desatando a su camello o a su buey para que no padeciera sed ni un solo día, cuánto más no estaría justificada la acción de desatar de su enfermedad a una mujer sujeta durante dieciocho años a ella.

Se advierten aquí algunos elementos importantes: a) la enfermedad es considerada un kathadesmós, ligadura o atadura; b) el causante de la enfermedad es Satanás. En los Evangelios, a diferencia de lo que ocurre en los Hechos de los Apóstoles y en los escritos de los Padres de la Iglesia, no se advierte una noción punitiva de la enfermedad, lo cual se acerca más a la concepción de la medicina hipocrática que a la del Antiguo Testamento. El milagro narrado en Lc. 14, 1-6 de la curación del hidrópico, guarda una notable semejanza contextual con el de la mujer inclinada, pues vuelven a aparecer la imposición de manos, a través del participio epilabómenos, tomándolo (de la mano) y el verbo apélysen, desató, con lo cual, el texto se lee así: "y tomándole lo curó y lo desató". Si bien no se atribuye aquí la etiología de la enfermedad a Satanás, tampoco hay referencia alguna a la índole moral del enfermo. La curación del ciego de nacimiento narrada en Jn 9, 1-41 resulta contundente en lo referido al rechazo de Jesús a considerar la causa de la dolencia como castigo por el pecado; c) el tercer aspecto, y tal vez el más importante, que destaca en el relato de la mujer inclinada, es la centralidad y prioridad del hombre y sus necesidades respecto del cumplimiento de la Ley. Los casos de posesión demoníaca obedecen también a esta etiología materialista de la enfermedad.

El otro origen de la enfermedad en tiempos del Evangelio, obedece a causas espirituales o sobrenaturales. Tanto la lepra, cuya curación se expresa a través del verbo katharídsein, limpiar (Mt 8, 1-4; Mc 1, 40-45; Lc 5, 12-16; Lc 17, 11-19), como la ceguera, cuyo proceso terapéutico involucra el verbo hépsato, les tocó (los ojos), se inscriben en esta modalidad etiológica (Mc 9, 27-31; Mc 8, 22-26; Mt 20, 29-34; Mc 10, 46-52; Lc 
18, 35-43; Jn 9, 1-41). Según los rabinos, tanto la hidropesía como la lepra provenían de un desequilibrio en los componentes del cuerpo. Consideraban que el hombre estaba compuesto por partes iguales de agua y de sangre. La salud obedece al equilibrio perfecto entre ambos fluidos, pero cuando peca $^{33}$, el agua predomina sobre la sangre y se hace hidrópico, o la sangre sobre el agua y se torna leproso. Al igual que los griegos, los hebreos catalogaban bajo la denominación de "lepra" toda clase de enfermedad cutánea de aspecto repulsivo ${ }^{34}$. En el Corpus Hippocraticum, por su parte, con el término lépra se hace referencia a lo que hoy se conoce como psoriasis $^{35}$, y habrá que esperar a la medicina helenística para encontrar tratados que describan la enfermedad que hoy se conoce con ese nombre. En cuanto a la ceguera, también coincidían con los griegos en que era el resultado del castigo divino a una falta cometida por el individuo o alguno de sus ancestros. Esa falta podía consistir en la contemplación de algo indebido, con lo cual la ceguera expresa la virtud de la divinidad ofendida. Con la reparación de la falta, la dolencia remite ${ }^{36}$. La acción terapéutica operada por Jesús en ambas enfermedades constituye un mentís a tales concepciones etiológicas. En cuanto a la lepra, en los dos casos en que se describe su curación en los Evangelios ${ }^{37}$, es la palabra imperativa de Jesús la que efectúa la curación. En el primer caso, Jesús extiende la mano, lo toca y dice: "Quiero, sé limpio". En el segundo caso, se trata de

33 Tal pecado consistía en la calumnia, la soberbia o la cohabitación con una mujer con menstruación.

34 En hebreo, sara'at, en el griego de los LXX, lépra. En documentos extrabíblicos parece aducirse como causa de la enfermedad la penetración de un espíritu de naturaleza más fisiológica que demoníaca. Así, por ejemplo, en algunos fragmentos de la cueva IV de Qumrán pertenecientes al Documento Sadoquita de Damasco y que no se encuentran en el texto más conocido de la Geniza de El Cairo. Cfr. R. North, "Medicina y terapias en el Antiguo Testamento", en A. Piñero (ed.), En la frontera de lo imposible, 93.

35 Los hipocráticos habrían atribuido erróneamente las enfermedades cutáneas al desequilibrio de los cuatro humores, como parece desprenderse de la lectura de dos placas de mármol en el templo de Asclepio en Epidauro, en las que se describen 48 curas para estos casos, de las cuales 46 acontecen durante los sueños de la incubatio mientras que solo dos son a base de ungüentos.

36 Cfr. Hch 9, 1-8: la ceguera contraída por Pablo en su conversión en el camino de Damasco y su curación por la imposición de manos de Ananías, y Hch 13, 8-12: la ceguera de Elimas el mago, acaecida por la invocación de Pablo ante el procónsul Sergio Paulo.

37 Un caso en Mt 8, 1-4; Mc 1, 40-45; Lc 5, 12-16. El otro caso aparece solo en Lc 17, 11-19. 
una curación a distancia de diez leprosos por la sola eficacia de la palabra y que acontece mientras iban a presentarse al sacerdote, de acuerdo a la orden de Jesús. Solo uno regresa para agradecer, un samaritano, cuyo linaje era considerado indigno por los judíos; Jesús pronuncia -una vez operada la curación milagrosa- la significativa expresión " $t u$ fe te ha sanado", con lo cual se advierte la referencia a la capacidad curativa intrínseca del propio cuerpo del sujeto, de la que el milagro actúa como catalizador.

La misma sentencia aparece en el contexto de la curación de la ceguera de Bartimeo en Jericó a través de la fuerza de la palabra, tanto en $\mathrm{Mt}$ 10, 52 como en Lc 18, 42, lo cual indica que la fe es condición necesaria para la realización del milagro, tal como se advierte en el incidente de Mt 9, 27-31 en que se combinan la imposición de manos y la manifestación de fe por parte de los ciegos: "Les tocó (hépsato) los ojos, diciendo: "hágase conforme a vuestra fe»" 38 .

El procedimiento terapéutico a través del tacto se aprecia también en el caso de los dos ciegos de Jericó: "Les tocó (hépsato) los ojos y al punto recuperaron la vista" 39 .

Mucho más complejo resulta el proceso de curación del ciego de nacimiento en Jn 9, 1-41, ya que guarda similitud con una técnica empírica de la medicina. Jesús escupió en el suelo, formó barro con la saliva y lo aplicó a la manera de un emplasto en los ojos del ciego, ordenándole lavarse en el estanque de Siloé. Este procedimiento presenta una estrecha relación con la concepción vigente en la época sobre la ceguera, pues esta enfermedad era considerada como una adherencia que puede eliminarse a través de un emplasto curativo aplicado sobre la misma y que al ser arrastrado con el agua se lleva también la causa material de la dolencia. En Mt 12, 22-30 la ceguera aparece unida a la mudez y se estima como la consecuencia de una posesión demoníaca. Si bien el procedimiento curativo no se describe, evidentemente responde a una típica terapia expulsatoria, pues, tal como Jesús advierte en su respuesta al reproche de los fariseos, no puede tratarse de una expulsión (ekbolé) en nombre de Beelzebú.

De todo lo expuesto hasta aquí, puede concluirse que los milagros de curación en tiempos de Jesús operaban por la palabra imperativa, por el contacto, o por una combinación de ambos. Por el contacto, se creía que

\footnotetext{
Mt 9, 29.

39 Mt 20, 34.
} 
la dynamis pasaba de Jesús al enfermo, concepción que si bien no se encuentra registrada en el AT, halla ciertos paralelos en la tradición médica helenística. A su vez, la forma de contacto podía variar entre un toque, un roce o la imposición de una o ambas manos, hasta el uso de sustancias materiales como la saliva o la tierra, coincidiendo en este caso con la concepción griega sobre las potencias curativas de la misma. Pero además, estas actividades maravillosas no deben ser separadas del contexto teológico para su comprensión, ya que se trata de signos de una realidad mayor que no agotan su significado último en el hecho en sí. De este modo lo entendieron también los gnósticos, cristianos profundamente inmersos en lo más arcaico de la tradición judeocristiana, quienes remontaban la interpretación de los milagros de curación o liberación desde el plano físico al alegórico, espiritual o simbólico. Teniendo en cuenta que la curación implicaría una complicidad del Salvador con la obra del Demiurgo del Antiguo Testamento al que rechazaban tajantemente, tales milagros apuntarían a la sanación de la psyché por la fe o por el pneûma, según la naturaleza antropológica del individuo. Por lo tanto, para estos cristianos, los milagros son los signos de la realidad precaria e imperfecta de este mundo ${ }^{40}$. En la misma línea, pero sin el rechazo a la dispensación antigua, Justino entiende que los hechos prodigiosos de Jesús son milagros en tanto constituyan una manifestación de la divinidad, único rasgo que lo distinguiría de un simple taumaturgo: "Pero se nos podría objetar: ¿qué inconveniente hay en que ese que nosotros llamamos Cristo sea un hombre que viene de otros hombres y que por arte de magia hizo los prodigios que decimos y por ello pareció ser hijo de Dios?”¹.

Justino se responde apelando al valor de la profecía, es decir, creyendo a los Profetas que anunciaron tales acontecimientos antes que a los testigos que los narraron o a los milagros en sí mismos.

\section{EL THEIÓS ANÉR Y LA FIGURA DEL MÉDICO: APOLONIO DE TIANA}

La categoría de hombre divino utilizada durante los períodos helenístico y romano resulta equívoca, ya que comprende una amplia variedad de

40 Para este tema, véase: F. García BazÁn, "En torno a Hechos 8, 4-24. Milagro y magia entre los gnósticos", en Revista Bíblica, año 40 (1978), 27-38; A. OrBE, Cristología gnóstica. Introducción a la soteriología de los siglos II y III, vol. II (BAC, Madrid, 1970) 15-58.

41 Justino, I Apología 30, en D. Ruíz Bueno, Padres apologetas griegos, 213. 
nociones dispares entre sí que comparten como rasgo común la creencia de que los personajes a los que les era aplicada disfrutaban de una relación muy particular con los dioses. Según un completo estudio del tema por Carmen Padilla ${ }^{42}$, esta denominación era aplicada a tres grupos distintos de personajes. En el primero, hay que incluir a los que se distinguen por alguna capacidad y actividad prodigiosa, tales como los profetas, magos y taumaturgos, fundadores de ciudades y héroes de nacimiento divino, como Heracles. Esta opinión es sostenida por autores como Günther Haufe ${ }^{43}$, investigador que sigue la línea de trabajos iniciados en el siglo XX por L. Bieler ${ }^{44}$ y continuados por R. Bultmann ${ }^{45}$, quien intenta relacionar esta figura prototípica con Jesús antes que con los taumaturgos helenistas influyendo de este modo en sus seguidores para la configuración de una cristología del hombre divino en orden a explicar el origen y desarrollo de la tradición de los milagros de Jesús. Algunos personajes a quienes según esta línea de investigación les cabe esta categoría, están incluidos en tradiciones legendarias que giran en torno a sus orígenes y actividades como maestros y taumaturgos, siendo Pitágoras el personaje arquetípico, cuyo nacimiento se asocia con Apo$10^{46}$. En esta pléyade de personajes extraordinarios se incluye un médico, Menécrates de Siracusa, cuya actividad taumatúrgica se orientaba con preferencia hacia la curación de epilépticos, los que una vez curados eran incorporados entre sus seguidores e investidos de dignidad divina por este médico, quien se consideraba a sí mismo Zeus ${ }^{47}$.

42 Cfr. C. Padilla, "Hombres divinos y taumaturgos en la antigüedad: Apolonio de Tiana”, en: A.A. Piñero (ed.), En la frontera de lo imposible, 149. La autora proporciona un importante catálogo de estudios sobre el tema.

43 Cfr. G. Haufe, "Religiosidad helenística popular", en J. Leipoldt - W. Grundmann (eds.), El mundo del Nuevo Testamento, vol. I (Cristiandad, Madrid, 1973), 83ss.

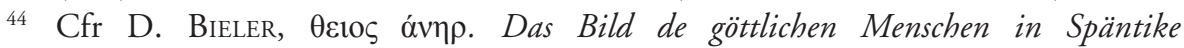
und Frühchristentum, 2 vols. (reimpreso en Darmastadt, Wissenchaftliche Buchgesselschaft, Viena, 1935-6, 1967).

45 Cfr. R. Bultmann Historia de la tradición sinóptica, Prólogo de Xabier Pikaza y Epílogo de Gerd Theissen (Sígueme, Salamanca, 2000) 267-301.

46 Cfr. Jámblico, De Vita Pythagorica 5, 7-8 y 10, en Jámblico. Vida pitagórica. Protréptico, introducción, traducción y notas de Miguel Periago Lorente (Madrid, Gredos, 2008) 29-31. Para comparar la relación entre Pitágoras y su condición divina según Jámblico con la que hace Porfirio en su Vida de Pitágoras, véase E. A. Jurado Ramos, "Jámblico de Calcis y el género biográfico", en HABIS 22 (1991), 283-295.

47 "Y no solo los reyes, sino también algunos particulares se honraron a sí mismos con denominaciones divinas, como Menécrates, el médico, ese que fue llamado Zeus”. 
En segundo lugar, suele aplicarse la denominación de theîos anér a aquellos hombres que se destacaron por su vida virtuosa y condición de sabios, independientemente de toda actividad taumatúrgica. En este sentido, trabajos como los de D. Tiede ${ }^{48}$ y L. Gil ${ }^{49}$ corrigen la perspectiva de Bultmann ya que distinguen los dos enfoques del hombre divino, a saber, el del sabio y el taumaturgo, separándolo de la asociación con el cristianismo primitivo $^{50}$. El gran estudioso español Luis Gil sostiene que en la Grecia arcaica esta categoría se aplicaba a los iatromanteis, quienes reunían en su persona la doble condición de médicos y adivinos. Entre ellos, Pitágoras, Empédocles y Epiménides de Creta; este último liberó a Atenas de una epidemia de peste. En cambio, el término se aplicó más tarde a aquellos hombres que, pasando desapercibidos en tiempos de ilustración, cobraron notoriedad en períodos de crisis ${ }^{51}$.

En Platón se encuentra separada la figura del sabio de la del taumaturgo, pues habla de los buenos poetas como poseídos por lo divino (euthousiadson $)^{52}$. Los estoicos, por su parte, asignan esta denominación al hombre sabio, quien, según Séneca, está muy próximo a los dioses ${ }^{53}$.

Clemente de Alejandría, Protréptico IV, 54, 3; introducción, traducción y notas de Ma. Concepción Isart Hernández (Gredos, Madrid, 1994) 114.

48 Cfr. D. L. Tiede, The Charismatic Figure as Miracle Worker (Society of Biblical Literature Dissertation Series 1, Scholars Press, Missoula, 1972).

49 Cfr. L. Gil, Therapeia. La medicina popular en el mundo clásico (Triacastella, Madrid, 2004).

50 No obstante, el mencionado G. Haufe comparte esta perspectiva.

51 Cfr. L. GIL, Therapeia..., segunda parte: "Médicos, Iatromanteis y 'hombres divinos", 59-83.

52 "De ahí que todos los poetas épicos, los buenos, no es en virtud de una técnica por lo que dicen todos esos bellos poemas, sino porque están endiosados y posesos. Esto mismo le ocurre a los buenos líricos, e igual que los que caen en el delirio de los Coribantes (Cfr. Eurípides, Bacantes 708ss.) no están en sus cabales al bailar, así también los poetas líricos hacen sus bellas composiciones no cuando están serenos, sino cuando penetran en las regiones de la armonía y el ritmo poseídos por Baco[...]”, Platón, Ion 533e-534a, traducción y notas de J. Calonge Ruiz, E. Lledó Iñigo, C. García Gual (Gredos, Madrid, 1981) 256-257.

53 "Ninguno pues, puede dañar al sabio o beneficiarle, porque las cosas divinas ni desean ayuda ni temen detrimento, y el sabio está muy próximo a los dioses y, excepto en la mortalidad, es semejante a Dios". SÉnECA, De la constancia del sabio VIII, 2, en: Lucio Anneo Seneca. Obras completas, trad. y notas de LorenZo Riber (Aguilar, Madrid, 1957) 218-219. 
En tercer lugar, se llamaba theioi andrés a aquellos que reunieron ambas condiciones, es decir, la conducta virtuosa y la actividad taumatúrgica. En esta clase de hombres se encuentran en su mayor parte los seguidores de Pitágoras, pertenecientes todos a épocas tardías. A pesar de la discrepancia entre autores sobre el alcance del término hombre divino es unánime la opinión de que el prototipo del mismo es Apolonio de Tiana. Hacia la primera mitad del siglo III, Filóstrato el Viejo dedicó a este personaje una biografía muy extensa y cargada de elementos prodigiosos que tienen el propósito de ensalzar esta figura como el paradigma de la fusión que se produjo en esa época entre religión y filosofía ${ }^{54}$. Según las noticias de Filóstrato, Apolonio nació en Tiana de Capadocia en el seno de una familia acomodada, y murió hacia el 96 o 98 d. C. Como fiel seguidor de Pitágoras - cuyas doctrinas conoció en Egas, donde existía un templo de Asclepio-, se esforzó en mantener la pureza de sus preceptos practicando el vegetarianismo y la abstinencia sexual. Fue un restaurador de cultos y de la pureza de sus ritos, así como un constante confrontador con los gobiernos establecidos en su época debido a su celo por la verdad. Filóstrato lo presenta como un daímon y un theîos anér para revertir su antigua reputación de mago y hechicero. Entre los relatos de milagro que se multiplican en la obra de Filóstrato, nos interesa resaltar solo aquellos que tienen relación con la medicina. Uno de los más notables es aquel que narra el modo en que libró a Efeso de una plaga previamente anunciada por él frente a la indiferencia de $\operatorname{todos}^{55}$. Al igual que Pitágoras que, según lo que dice Filóstrato, estuvo en Turios y Metaponto al mismo tiempo, Apolonio se trasladó a Efeso de forma maravillosa con solo decir vayamos. Una vez allí, reunió a la

54 Filóstrato pertenecía al círculo literario de Julia Domna, esposa del emperador Septimio Severo y es posible que esta biografía haya sido escrita por encargo de la emperatriz, ya que la simpatía de la familia imperial hacia Apolonio de Tiana llegaba al punto de que Alejandro Severo, último miembro de la dinastía de los Severos, rendía culto a Apolonio en su santuario privado, junto a las figuras de Cristo, Abrahán y Orfeo. Esto es una muestra del profundo sincretismo al que se había llegado en la época. Cfr. S. M. Lezcano Rejano, "Orfismo en el Corpus Philostrateum”, en Emerita. Revista de lingüistica y filología clásica (EM), LXXI, 1 (2003), 51-72 (aquí: 59, n. 27).

55 Cfr. Philostratus, The Life of Apollonyus of Tiana. The Epistle of Apollonyus and the Treatise of Eusebius (en adelante: VA), IV, 4, vol. I, ed. bilingüe griego-inglés, trans. F. C. Conybeare (W. Heinemann LTD - Cambridge, Massachusetts, Harvard University Press, Loeb Classical Library, London, 1969), 355. 
población alentándola con palabras que prometían el fin de la plaga y luego se trasladó con ellos al teatro. Allí encontraron a un mendigo que pedía limosna, pero ante la sorpresa de todos, Apolonio ordenó que lo apedrearan. Frente a la impotencia de la gente movida por la compasión, repitió la orden y comenzaron a lapidarlo. En ese momento, en lugar del mendigo apareció un gran perro rabioso cuyos ojos despedían fuego. De este modo alejó la plaga de Efeso $^{56}$. Este milagro epidemiológico, antes que describir alguna actividad taumatúrgica pone el acento más bien en la sabiduría de Apolonio para conocer el origen del mal. Entre otros milagros, se cuentan el de la liberación de un joven poseído al que la gente creía trastornado por su juventud ${ }^{57}$, la reanimación de una joven muerta en el día de su boda ${ }^{58}$, la asistencia para recobrar la cordura a un enamorado de Afrodita que quería casarse con la estatua ${ }^{59}$ y la cura de la rabia a un joven mordido por un perro, haciendo que el mismo perro lamiera la herida. Al perro que lo atacó, lo obligó a cruzar el río para vencer la hidrofobia, rasgo característico de esta enfermedad ${ }^{60}$.

De las treinta y cuatro narraciones sobre la actividad taumatúrgica de Apolonio que recoge Filóstrato, los relatos de milagros de curación y reanimación de cadáveres intentan poner de manifiesto la sabiduría de este personaje en discernir lo oculto por sobre lo aparente antes que la actividad taumatúrgica en sí misma ${ }^{61}$, de lo cual se desprende que las figuras del theîos anér y del médico no se encontraban necesariamente contrapuestas.

\section{CONSIDERACIONES FINALES}

De todo lo anteriormente expuesto puede comprobarse que en la tardoantigüedad, tanto la medicina como la religión, el milagro y la magia no podían separarse con facilidad en la mentalidad popular. La realidad de los milagros era aceptada por los hombres cultos de la época, a punto tal que la negación que hace Celso de la veracidad de los milagros de Jesús en general y, en particular de los de curación, obedece a su necesidad de

\footnotetext{
Cfr.Philostratus, VA IV, 10-11, 363-369.

Cfr. Philostratus, VA IV, 20, 389s.

Cfr. Philostratus, VA IV, 45, 457-459.

Cfr. Philostratus, VA VI, 40, vol. II, 134-139.

60 Cfr. Philostratus, VA VI, 43, vol. II, 140-143.

61 Cfr. C. Padilla, "Hombres divinos y taumaturgos en la antigüedad...”, 155s.
} 
desprestigiar la figura del Nazareno atribuyendo sus portentos a la magia antes que al poder de Asclepio, a quien Celso tenía en alta estima ${ }^{62}$.

Mientras la religión se dirige a seres poderosos y de carácter personal para la realización de un hecho portentoso en beneficio o maleficio de alguien, la magia opera sobre la creencia en un campo de fuerzas convergentes cuyo conocimiento y control posibilita que acontezca la curación, en el caso que nos ocupa. No obstante, esta distinción no resulta del todo clara ni desde el punto de vista científico ni del de la historia de las ideas, así como tampoco del fenomenológico.

El advenimiento de la medicina racionalista produjo un desplazamiento de la confianza en las potencias curativas propias de la physis humana hacia la sapiencia o habilidad técnica del médico y la presunta eficacia de los remedios. Esta sustracción del elemento fundamental de la intuición médica más originaria produjo una crisis que se vio profundizada por el imperio del cientificismo craso, deformación ideológica de la ciencia que, desafortunadamente, goza hoy del reconocimiento generalizado como única forma válida del saber. Este modo lacerante y deletéreo del racionalismo contemporáneo redujo la filosofía y la religión a las exigencias del empirismo científico y de oponer al dato fenoménico una verificación en los únicos términos admitidos por la racionalidad cuantitativa, con lo cual traiciona y desborda la estructura misma de la ciencia. Los extraordinarios avances de la biotecnología médica se abren de este modo en un horizonte deshumanizado e impersonal, con lo que se afecta de manera dramática la relación médico-paciente. El profundo sentido de humanidad que caracterizaba la antigua práctica médica, integradora y totalizante, interpela a la práctica médica contemporánea reclamándole un enfoque centrado en lo antropológico sin desestimar los indiscutibles logros científicos y tecnológicos experimentados por la medicina que, como ciencia prerrogativa de lo humano, debe subordinarse a la prioridad indiscutible de los intereses, voluntad y decisión del enfermo.

62 Cfr. Orígenes, Contra Celso III, 22-23; introducción, versión y notas por D. RuIZ Bueno (BAC, Madrid, 1967) 190-192. 